\title{
Strategies and politics of ocupational stress reduction - case study
}

\author{
Mihaela-Georgia Sima, Bucharest Chamber of Commerce and Industry, Romania \\ Simona-Clara Bârsan, Research Institute for Analytical Instrumentation Cluj-Napoca, \\ Romania
}

\begin{abstract}
This work includes 2 parts: main theoretical elements and 1 case study. Theoretical elements define and explain concepts such as: stress, stress management, counseling and organizational change. In the case study these elements are applied on a research unit development. The reason for the analysis was the tense situation existing in the company. Work methodology included: observation, direct discussions with staff (in small groups) and the application of a questionnaire consisting of 6 modules. On that base, major dominant stressful manifestations were determined. Following the obtained results solutions have been proposed to management and employees. In the last part, there are presented the obtained results from the implementation of some of proposed solutions.
\end{abstract}

\section{Key words}

stress, management, counseling, organizational change, results

\section{JEL Codes: M 12}

\section{Introduction}

Whatever we do in life, we often experience stress. A study conducted by Reader's Digest in 15 European countries showed that, at present, the Romanians have "managed" a spectacular counter performance: we are number 1 in Europe at perceived level of stress: $52 \%$ believe that stress is the greater health problems, compared to European average of $33 \%$. Stress is not necessarily something negative, characterization as negative or positive stress depending on each situation. Up to a certain limit, the stress is even necessary to our business.

\section{Theoretical elements}

\section{Stress}

Positive stress is necessary for our protection, for example in case of an accident by mobilizing all body resources in order to avoid it. In this case, we speak of a positive stress because in a stressful situation, typical stress reactions of the body show - heart begins to beat faster, the brain receives more oxygen, the muscles are tense and so on - but for a positive resolution of the situation.

The negative stress is a reaction to the inherent psychological stressors demands that have the potential to make a person feel tense and anxious, because he or she is not able to face these demands. It is a tension that arises when a person responds to job demands, family and other external sources as if they were generated by its internal needs, obligations and selfcriticism. Stress is both additive and cumulative. In time it accumulates up to the state of crisis when symptoms appear. These can manifest physically by: irritability, anxiety, concentration decreased, frustration and hatred. Also physical symptoms can occur: muscle 
tension, headaches, back pain, insomnia and hypertension. Untreated, symptoms may lead to illness and even death.

\section{Stress management refers to:}

a. Identifying causes which produce and adopt measures such as: individual responsibilities change (reduction or increase them); increased autonomy in carrying out tasks; agreeing to employee goals; providing appropriate training (eg in time management techniques); allowing adoption of a flexible schedule; offering professional and personal counseling; improved working conditions; employee relocation; providing access to the sports centers (e.g.: Many Japanese companies insist their employees workout at the beginning of a working day).

Helping employees in developing the capacity to cope better with stress by: providing counseling services; organizing working sessions on stress; sports and social activities; training in relaxation techniques; serving meals and providing spaces for adequate rest.

Counseling is essentially a discussion (a series of talks) between the person who needs help (the client) and another person who masters the techniques of counseling. Managers should know such techniques if they wish to solve effectively their subordinates' problems and obtain maximum results.

Counseling is a process that helps clients to:

1) identify the problem;

2) to determine which would be ideal or preferred outcomes;

3 ) to explore ways of achieving results.

Besides the specialists within the human resources compartment (economists, sociologists and psychologists) an extremely important role falls upon managers at all hierarchical levels, from top managers to team leaders because they are the ones who work directly with people, who create a climate, those who know them best and who can think, with the support of specialists, the best solutions and most important, who can actually implement them.

\section{Organizational change.}

In contrast to stress management and assistance programs for employees, some organizations try to reduce stress by using a specialized consultant who is responsible for recommending some ways for improving working conditions. This approach is the most direct way to reduce stress at work. It involves identifying the most stressful aspects of work (e.g. overwork, conflict) and design strategies to reduce or eliminate the identified stressors. The advantage of this approach is that it treats directly the main cause of stress at work. However, sometimes managers do not agree with this approach because it involves changes in work routine, production schedule or in the organizational structure.

As a general rule, actions to reduce stress at work should pay particular attention to organizational change in order to improve working conditions. But even the most conscious efforts to improve working conditions are unable to eliminate stress completely for all employees. Therefore, a combination of organizational change and stress management is often the most useful approach to prevent stress at work.

Case study: research and development unit of public utility.

\section{Methods:}

In order to identify stressors, the following methods were used: passive observation (a 3 days period), informal discussions and an inventory of stressors. 
Passive observation - Observation was done over a period of 3 days, was a simple observation, direct, discontinuous. Data were recorded following each stage of observation. The purpose was to make an observation of the original image on the environment, activity and behavior caused by this environment. By observation we distinguished characteristic manifestations from the random.

Informal discussions - were held in small groups (2-3 employees) and focused on grievances, problems and difficulties they meet in their work. Conversations with employees were the most direct way to find out details of the motivations, aspirations, emotional experiences, interests. Following that discussion an inventory of stressors was made. This inventory was then submitted to all employees and constituted the support for differentiation of stress levels present at employees.

In order to complete the data a 6 modules questionnaire on stress at work was used:

Work requests: My work requires me to work very quickly. My job makes me work hard. I am not required to provide a large amount of work. I have enough time to finish my work. My work requires me long periods of intense concentrationMy tasks are interrupted before they are finished and I will have to pay attention to them later. My job is very hectic. Pending due to other colleagues or departments slows down my work.

Decisional authority: My job allows me to take many decisions. At work, I have little freedom to decide how to do my work. I can determine the order in which I finish my tasks. I can determine when I need to fulfill a task I can easily go away from work for a short period. I can set my own working rhythm. I feel that my work gives me a place in the community.

III. Abilities: My work requires me to learn new things. My job involves a lot of repetitive work. My work requires me to be creative. My work requires me a high level of skills. I have to do different things in my work. I have the opportunity to develop my specific skills.

IV. Working contract terms: I can determine when to start and finish work. I can determine when I need a break. I know my work schedule a week before. I can determine when to take my holidays. The health and safety norms are well known and respected. Prospects for my career development are good.In five year time, my skills will still be valuable. I have the opportunity to attend training courses, specialization and training. My wages is satisfactory. V. Bosses and colleagues' aid: The atmosphere at work is good. Most of the people irritate me. If needed, I can call in for help one or more colleagues. Where I work, daily order is good. My work is properly appreciatedI'm informed about the situation of the company. I feel free to discuss problems and complaints with companies' management. My suggestions regarding changes in working practices in order to streamline work are taken into consideration. Magazine company (if any) is useful If there is no magazine, don't answer.

VI. Socio-demographic: Sex; Age; Marital status; Family component: number of members.... out of which hildren .........; Training level; Activityfield: public service; other: research projects; Personal income; Income per family member; City: Bucharest

\section{Stressors inventory.}

From discussions the following dominant stressors resulted:complaints about career: the impossibility of advancement; conservatism in terms of job design; conflicts with superiors, colleagues, subordinates and customers of the company; contradicted requirements from the institution; unstructured or unclear objectives; inadequate resources; conflicts between the needs and expectations; bad working conditions (noise, faulty lighting, lack of performing equipment); inadequate time management; routines; overload; poor management of potential and skills of employees in the way of not-exploiting resources, capacities, skills; responsibilities on other people; unrealistic deadlines, inadequate schedule; conflict between home demands and those from work; lack of free time; family and housing conditions; financial status; insufficient sleep; legislative changes; the risk of occupational diseases; poor communication.

The substantial presence of following stress indicators was noticed: high level of sickness; 
headaches and stomach aches; mental states such as absenteeism, apathy, embarrassment, boredom, dissatisfaction, fatigue, alienation, anger or irritability, negativism; low productivity and inability to achieve the objectives set forth; increased error rate; increased number of internal conflicts between employees, excessive rate of staff fluctuation, phenomenon increasing while time passes by.

\section{Proposed Solutions}

Because a fairly large number of employees expressed dissatisfaction about the same issues, we believe that they are active factors of stress. So the stress reduction strategy will focus mainly on reducing them.

The solution we proposed is a combination of a stress management with organizational change.

It is necessary to be mentioned that the contribution of both parties, especially their readiness to achieve a positive result, respectively a not tensioned and productive working atmosphere, an environment in which the human potential that exists in the organization is able to express and develop.

Thus, after the analysis, the following recommendations can be made:

\section{For management:}

It is recommended: that specialized programs, involving all employees at a time, are to be developed, in order to enable wider perspective on the possibilities offered by working with companies' clients. Apart from these courses, there may be some changes within the institutional behavior by promoting friendly attitudes between management and employees of the institution. These can start from the management or from the employees. In this way the managements' image of the employees may improve and the employees can evaluate, diversify and develop professional capabilities.

Participation in specialized courses enables interaction with other leading business media and professional re perception of the employees' activities.

Evaluation of this strategy can be made after at least 6 months, time required in order to assure the participation of at least one set of employees at specialized courses related to the effects of less formal atmosphere due to behavioral changes. A form of assessment could be done through interviews.

2. To improve communication between management and employees, besides the possibility of friendly relations, meetings can be organized involving both management and employees where they can express every opinion. An indicator of good communication is the degree in which the chief and subordinate agree on job issues and each is sensitive to other's point of view. It may be that the parties "agree they disagree" in some respects. These meetings aim to present several points of view and to emphasize that those can lead to expected results. Agreement between the parties "implies increased confidence in the professionalism of others. Training team work spirit aims to increase the efficiency by improving interpersonal relationships, clarifying goals and roles (what is the team trying to achieve and who is responsible?). It can thus facilitate communication and coordination. Training team spirit usually begins with a diagnostic session, "often kept out of work, in which the team examines their current level of functionality"[4]. Because our group' main factor of stress involves extended working hours, the opportunity of doing these sessions away from the workplace is appropriate.

3. Defining jobs in a manner that allows a maximum freedom of exercising the skills and discernment of the job' owner, in order to maintain the interest for the position.

Design activities so that the employee should have a certain degree of responsibility, sufficient authority and the right to participate in decisions that influence its activity. 
5. The way employees are treated should give confidence about job security and the position they occupy in the institution.

Addressing inadequate generally leads to conflicts, and when they cannot show it creates a complex kind of "impotence" which maintained, creates a constant state of stress.

Providing counseling services for employees, internally, using their own qualified advisors, or resorting to the services of an outside consulting organization. In this way the organization obtains several advantages using minimal resources. For example: a good external image (the company is interested in the welfare of employees), different employees' attitude towards the management of the institution (including reducing of conflicts frequency), compared to the work they perform, high efficiency, intellectual comfort and so on. In terms of resources used, comparing the financial problems that may arise from inefficient work or stuff fluctuation, it can be easily concluded that in fact this will not be considered a substantial effort.

8. Create optimal conditions for work - adjusting locations in accordance with occupational health, providing required equipment in order to perform duties.

9. Where there is lack of possibilities for material reward, it is recommended to provide other facilities, eg granting time off, merit and performance recognition in public.

10. Identifying the right person for a specific job - execution, management. This may lead at the same time to: the optimal use of human potential, rewarding the deserving, avoidance of conflicts arising between employees on grounds of incompetence, unnecessary loading of the work of some others, allowing the direct superior to delegate his power because he will do it efficiently.

11. Implementing a management system that takes into account the fact that people have also have family problems, such as taking children to kindergarten, and therefore to accept the request of the employee to a flexible or lagged working program. Thus we obtain multiple benefits: the employee is satisfied that he/she is understood and helped, personal problems are solved, and the institution benefits from a stable committed and flexible enough employee (considering that they agree to the working conditions and benefits they get from the institution).

\section{For employees:}

Learn to manage stress in order to ensure long-term professional success and to maintain physical and mental health:

1. Change of perspective. For those employees who think the employer requires too much (quite a big number), it is advisable to check if the problem lies within its personal organization or the way that the department is operating. It is better to turn to a career counselor to make an action plan, which will lead in time to the intellectual and personal comfort.

2. If tension or stress is felt, a five minutes break it is recommended outside the working space, away from work routine. There has been noticed in time that this contributes to a significant stress decrease.

3. Respect the time dedicated to family or itself. It is important to leave work at the office, in all the cases. Decreasing personal time in favor of the professional one has proven to be a powerful stress factor, regardless of the individual position on the social ladder.

4. Organizing the workplace and tasks, keeping a list of priorities and supervising them. Feeling overloaded and out of control are situations that cause stress.

5. Manifestation of personal feelings towards a close person. The existence of support, of a person who wants to listen, helps relaxation and reduces stress.

6. There certainty that help exists in situations of overload will decrease the tension. But that relationship should be work both ways, from the transmitter to the receiver and back, because in time, roles can reverse and the one who help in a certain situation must be sure that the same support will come back from the one who's been helped now, when a similar 
situation should appear.

7. Laugh therapyAlmost any situation can be relaxed through a joke or a good disposition created by a man with a sense of humor.

8. Too high and unrealistic expectations of what can be done in a day, week or month can cause negative feelings. High levels of stress negatively affect motivation and influence professional outcomes. In time, a very capable and performing professional, but unmotivated properly, will come to point of not providing appropriate outcomes.

9. The idea of perfection has to be dropped. No one is omnipotent.Failures don't have to be lived dramatically, but viewed positively and considered ways of learning from their mistakes.

10. A positive attitude is recommended, avoiding negative people with a bad attitude because they can "contaminate" others with their behavior. Negativism destroys energy and motivationA positive atmosphere needs to be created around people with which one interacts and within the working environment. Achievements should be a cause for joy, even when nobody else feels the same.

\section{Implemented solutions - Obtained results}

Following the analysis and the proposed solutions, management has decided to organize a delegation of three days in Mangalia, involving a part of the company's staff.

Although the main purpose of the delegation was work, the delegation's evolution from a psychological and behavioral perspective was a positive one during the three days.

Starting from a general and permanent state of stress, manifested in various ways, from the high tones of voice to expressed depressions, in the second night a state of relaxation and good communication within the team was reached, which has generated a good mood, maintained after the return to work.

As each, at a time, felt able to express itself freely, without regard to function, age and corporate position, the atmosphere was relaxed, accounts adjusted and nerves exhausted.

Even though organizational problems arose during the delegation, they were treated with more relaxation than normal, and clearly resolved quicker and more efficient.

The applied solution was very simple and less expensive for the company, with maximum results.

Multiple outcomes were registered:

Delegation target was achieved, cooperation between the analyzed company and hosts was perfected, joint projects have been proposed, convenient for both parties;

- People to work more relaxed, returned as more than daily colleagues, depending on compatibilities, constructing or deepening a friendship relationship and they became to know each other better than they can do it in the office;

- In terms of the impression created by the analyzed company's management, one can argue that using a reduced amount of money, yet something was offered to its employees, which tempered, at least for a while, reluctant and nervous attitude shown before.

\section{Conclusions}

In terms of stress there are 2 main ways of approach: total ignorance, with negative results or amplify the importance of the phenomenon and justify the majority of failures on its expense. We believe that no one's approach is neither normal nor useful for companies or employees. A middle way is always best. Far from us the idea of reducing the importance of this element within daily activities, but we do not believe that stress is responsible for all failures, whether personal or professional. Thus, from our experience, we recommend to the institutions and employees to consider the evidence presented in this work, both as theory, and practice and 
seek to apply, according to the specific job, one or more of the solutions we proposed. Obviously, depending on stress factors and dominant manifestations that result from an analysis, other solutions might be proposed. Therefore we consider it appropriate for everyone, before you diagnose by ear or take a position depending on appearances, to make a brief analysis of the reasons which lead to disruption of the daily activity of everyone.

\section{References}

1. Adirondack, Sandy (1999) Managementul pur și simplu?,, Ed. F.D.S.C. , Bucureşti

2. Cosmovici Andrei (1996) Psihologie generală, Ed. Polirom, Iasi

3. Cristea, Dumitru (2000) Tratat de psihologie socială, Ed. Pro Transilvania, Bucureşti

4. Johns, Garry (1998) Comportamentul organizațional, Ed. Economică, Bucureşti

5. Minulescu, Mihaela (1996) Chestionarele de personalitate în evaluarea psihologicăa, Garell Publishing Haus, Bucureşti

6. Nestor, I. M. (1974) Psihologia industrială-Considerații practice de organizare, Ed. Politică, Bucureşti

7. N. I. O. S. H. (National Institute for Occupational Saftey and Health), (2002) Niosh Stress, U.S. Departament of Health and Human Services

8. Selye, H. (1974) Știință și viață, Ed. Politică, Bucureşti 